\title{
Never mind the quality: feel the improvement
}

Getting busy practitioners to learn about and to take up quality improvement is difficult. Demanding work schedules and external work stressors are among the barriers. Not surprisingly, there are only a few examples of implementation of continuous quality improvement in primary care. In settings other than health care it seems that approaches to improvement-such as continuous quality improvement - that include everyone and work through scrutinising working practices-can catalyse tangible benefits. Translated into health care such results would include improvements in the organisation and the processes of care that should benefit both patients and staff.

The many factors that lead to the uptake of continuous quality improvement are well known. ${ }^{12}$ Good leadership is important. To be successful continuous quality improvement is dependent on the involvement and commitment of the whole team. A key factor is that all staff must perceive a need to find better ways of meeting the needs of their patients or clients. The methodology includes taking a systems view of the processes of care. The views of all team members must be heard and valued and the tacit knowledge and expertise of each team member recognised. Team members should have a shared understanding of how each either directly or indirectly effects the delivery of care to patients. This provides a necessary depth and breadth of knowledge and understanding about the processes of care that should highlight high leverage points in the system of care in which redesign is likely to lead to improvement. ${ }^{3}$

Many of these characteristics would seem to describe an approach synonymous with good organisational practice. That introducing continuous quality improvement into health care is difficult suggests some inherent problems with traditional structures within health care. In this issue of Quality in Health Care Hearnshaw et al highlight some of the difficulties and dilemmas that emerged when quality improvement programmes were implemented into primary care. ${ }^{4}$ Firstly, as others have found, the uptake (even when free facilitation is on offer) is very low. The benefits simply cannot be perceived to outweigh the costs. But what those perceived costs are is not clear. Secondly, the tendency to hierarchical teams make it difficult to build decision making around consensus. And, thirdly, as others have described, in this study, it was in those teams in which doctors were not committed to the process that implementation of quality improvement was the most difficult. ${ }^{25}$

Awareness of the need to consider quality issues and identification by the team of quality improvement as the means of achieving those objectives are prerequisites for its successful implementation. Education is a means of increasing awareness and providing necessary skills. But asking busy staff to take time out to attend courses run by others, which may seem to be conceptually distant from their working lives, may not be the best way to achieve this. Creating protected time and space within the practice and allowing necessary concepts to be introduced in the context of the team and its current local issues are likely to be more effective, and enable the improvement project to be a learning process in its own right.

Quality improvement through building in simple and balanced sets of measures - for example, clinical outcomes, state of health, satisfaction versus need, total costs ${ }^{6}$-allows teams to check the consequences of changes and makes the whole process a powerful tool for learning. This can be fun and stimulating, and encourages a climate in which measurement is used to identify areas for improvement and check the effects of change, rather than for judgement, control, or finding someone to blame. ${ }^{1}$ None of this is of course new to some practitioners. Many adults learn best when focusing on practical and concrete activities and drawing the theory out from reflection on these. ${ }^{1}$ Despite the problems, improvements were stimulated through the experientially based programme described by Hearnshaw et al. That some of the practices were still able to describe benefits 3 years later reinforces the potential value of such an approach.

There are clear links between quality improvement and education. Programmes such as the one described by Hearnshaw et al aim to provide education and support for quality improvement, but as they state, the commitment and time must come from within the team. It seems that whether a team is prepared to take up quality improvement is dependent on pre-existing team characteristics as well as the importance of the topic. Group working, team building, and leadership skills are all necessary for many aspects of work and are essential skills for quality improvement. If programmes like this one are to succeed further the educational effort needs to include a focus on the development of good team and group skills. Explicit training in any of these is missing from most undergraduate education for health professionals. Lack of these skills may have an impact on many aspects of work but is highlighted when attempts are made to introduce quality improvement programmes. The difficulties and consequences for groups that include doctors who are unfamiliar with group working processes have been described. ${ }^{7}$ Introducing quality improvement is likely to be a difficult process unless participants already have the necessary basic skills. However, tackling a quality improvement project with a shared vision and purpose can also serve as a driving force for developing these skills.

We think that through strategies based on continuous quality improvement practice teams can move from a wish to improve the delivery of care to planning and implementing change that results in real improvements to patient care. ${ }^{8}$ If this is to be integrated within the routine work of health care, educational programmes - such as the one described hereare not enough. Knowledge about continuous quality improvement, underpinned by the skills of team and group working, is the missing link between the rhetoric and the implementation of quality improvement. These should be considered as a fundamental part of professional development and should be included in undergraduate and postgraduate courses for all healthcare professionals.

PETER M WILCOCK

Chartered Clinical Psychologist

CHARLES CAMPION-SMITH

Associate Director of General Practitioner Education, Institute of Health and Community Studies, Bournemouth University, UK

1 Headrick LA, Wilcock PW, Batalden PB. Interprofessional working and continuing medical education, BMf 1998;316:771-4.

2 Irvine D, Irvine S. The practice of quality. Oxford: Radcliffe Medical Press, 1996.

3 Nelson G, Batalden P, Plume S, et al. Improving health care: part 2-a clinical improvement worksheet and users' manual. The foint Commission fournal in Quality Improvement 1996;22:8.

4 Hearnshaw H, Reddish S, Peddie D, et al. Introducing a quality improvement programme to primary healthcare teams. Quality in Health Care 1998;7:200-8.

5 Lawrence M, Packwood T. Adapting total quality management for general practice: evaluation of a programme. Quality in Health Care 1996;5:151-8.

6 Nelson G, Mohr J, Batalden P, et al. Improving health care: part 1-the clinical value compass. The foint Commission fournal on Quality Improvement 1996;22.

7 Newton J, Hutchinson A, Steen N, et al. Educational potential of medical audit: observations from a study of small groups setting standards. Quality in Health Care 1992;1:256-9.

8 Campion-Smith C, Wilcock P. Interim report, Dorset seedcorn project [internal report]. Bournemouth: Institute of Health and Community Studies, Bournemouth University, 1997. 